\title{
Adaptive Steam Temperature Regulation for Essential Oil Extraction Process
}

\author{
Mazidah Tajjudin ${ }^{1, *}$, Mohd Hezri Fazalul Rahiman ${ }^{1}$, Norlela Is hak ${ }^{1}$, Has himah Is mail ${ }^{2}$, \\ Norhashim Mohd Ars had ${ }^{1}$, Ramli Adnan ${ }^{1}$ \\ ${ }^{1}$ Faculty of Electrical Engineering, University Teknologi MARA, 40450, Shah Alam, Selan gor, Malaysia \\ ${ }^{2}$ Faculty of Engineering, University Selan gor, 40450, Bestari Jaya, Selangor, Malaysia
}

\begin{abstract}
Essential oil is volatile and sensitive to excessive heat. Many studies had shown that temperature during extraction process had a great impact on the oil quality. Despite of that, until now there are very few research had been published on the controldevelopment of essential oil extraction system. Hence, this study was commenced particularly on the development of a regulated essential oil extraction system using self-tuning control. A self-tuning control was applied using pole-assignment method to regulate the steam temperature throughout the extraction process. Combination of controller poles in real and imaginary axis may influence the closed-loop response so that the steam can reach the set point faster but yet with minimal overshoot. Extensive analysis was done by simulation in order to understand the effect of the poles location and also the selection of sampling time over the closed-loop response. Outcome from the simulation was applied on the real process where the controller produced satisfactory result as expected. The controller was able to regulate the steam temperature at a desired level and maintained within $\pm 2 \%$ output boundary.
\end{abstract}

Keywords Self-Tuning PID, Steam Distillation, Essential Oil Extraction, Pole-Assignment, Recursive Least Square

\section{Introduction}

Steam distillation is among the most popular method for essential oil extraction process. The proportion of different essential oils extracted by steam distillation is $93 \%$ and the remaining $7 \%$ is extracted by other methods such as hydro distillation[1]. This method applies hot steam to extract the essential oil from the raw materials. The mixture of oil and steam will be condensed and separated at their liquid form. In the majority of cases the oil is less dense than water and so forms the top layer of the distillate and can be separated easily using proper method and instruments.

Continual exposure to excessive heat may degrade the quality of the essential oil as had been studied and reported in[2] for ginger extraction. The study proposed that steam temperature needs to be regulated below saturated temperature throughout the extraction process. This finding had been supported by lots of other published works [3-7]. Nevertheless, there were very few literature on the control development for extraction system was found.

This study initiates the development of an automated essential oil extraction system us ing steam distillation

* Corresponding author:

mazidah@salam.uitm.edu.my (Mazidah Tajjudin)

Published online at http://journal.sapub.org/control

Copyright (C) 2012 Scientific \& Academic Publishing. All Rights Reserved technique. The system was able to perform steam distillation at a regulated temperature up to $100^{\circ} \mathrm{C}$.

Steam temperature control had been studied and applied using various methods. Most of the publications focused on the superheated steam temperature control. There is very little publication so far that discussed on the steam temperature regulation below $100^{\circ} \mathrm{C}$. Nonetheless, other studies pointed out the same non trivial issues in steam temperature regulation which is normally comes from the nonlinearity, slow varying process dynamics, fast disturbance and unmodeled dynamics[8-11]. Dynamics of the process may be changed due to load variations and sometimes from unpredictable causes. These attributes made fixed parameter controller such as PID is inefficient to perform satis factory control for steam temperature.

It is not doubtful that PID controllers are still widely used in industries nowadays despite of the advancement in process control technology. It has been reported that more than $97 \%$ of the controllers in process control industries are of PID type[12]. The ability of PID control mode to compensate most practical industrial processes has led to their wide acceptance such as in pulp and papers industries. In addition, it simple structure and easy to understand has made tuning procedures more easy to comprehend and can be accomplished by trial and error by technical personnel. Furthermore, the presence of integral term will ensure zero steady-state error for a step change in input signal. 
Nevertheless, PID controller will only performed well within limited operating range where tuning was performed unless the process is linear. Unfortunately, even though the control structure seems simple, there were no generic tuning procedures that can sustain satisfactory performance over variation of process types. This drawback has led to continual research in PID control leading to different kind of tuning approaches. Some of the renowned methods applying phase margin and gain marg in, the internal mode control (IMC) design method, direct synthesis method, graphical technique, optimization technique, and frequency response analysis[13]. An extensive summary of some well-known PID tuning techniques can be found in[14]and[15].

An adaptive PID or the self-tuning PID on the other hand will automatically adjust the controller parameters based on the control laws. Th is control scheme is attractive especially if there is only little information about the process to be controlled is known. In fact, there are lot of on-going research in refining the algorithms to tailor the needs of specific applications[16].

This paper focused on applying the self-tuning PID to regulate steam temperature in steam distillation process for essential oil extraction. Steam distillation process possessed a slow varying dynamics with varying time-delay and process gain over its full-range. Specific operating range need to be identified where the control can be acco mplished successfully. The process was described by autoregressive with exogeneous input (ARX). The unknown parameters were updated using Recursive Least Square (RLS) method while controller design was based on pole placement.

An overview about steam distillation for essential oil extraction process was discussed in Section 2. Section 3 explained on the self-tuning control design and algorithm using pole-placement method. Some simulation results to show the effect of poles selection will be discussed in section 4. The simulation will then be verified with experimental evaluation in section 5 .

\section{Steam Distillation Essential Oil Extraction Process}

A pilot-scale steam distillation plant developed for this study consists of a stainless steel column of $26 \mathrm{~cm}$ inner diameter and a vertically mounted steel condenser to convert the steam into liquid form. Figure 1 shows the simplified schematic diagram of the plant. Two RTDs were installed; RTD1 was immersed in the water to monitor water temperature while RTD2 was installed $40 \mathrm{~cm}$ from RTD1 to monitor the steam temperature inside the column. The distance of the sensor from its heat source will caused transport delay in steam temperature measurement.

During operation, steam will be generated by boiling the water inside the distillation colu mn. In normal operation, the water volu me is 6 litres. The water was heated up by a $1.5 \mathrm{~kW}$ coil-type heater. It took about 3500 s to boil the water. The open-loop response under normal operating condition is shown in Figure 2. Column temperature that represents the steam temperature started to rise gradually after 1500 s when water temperature is around $70^{\circ} \mathrm{C}$. The steam temperature increased exponentially until $80^{\circ} \mathrm{C}$ where the steam rate hiked to $100^{\circ} \mathrm{C}$ and saturates. During this state, temperature within the column is at homogeneous.

The objective of this research is to regulate the steam temperature below $100^{\circ} \mathrm{C}$ as to preserve the oil from burning and consequently preserving its quality. During closed-loop operation, the steam temperature will be measured by RTD2. RTD2 was installed over the raw material to monitor the temperature of steam that passed through the raw material instead of measuring the steam temperature that will enter the raw material bed.

Some signal conversion needs to be done to convert the resistance from RTD to voltage signal that was compatible with the acquisition card PCI 1711. The signal converter converts $0^{\circ} \mathrm{C}$ to $120^{\circ} \mathrm{C}$ to $1 \mathrm{~V}$ to $5 \mathrm{~V}$. This signal was the measured variable of the process. Control signal from the controller manipulated the heater power by providing a d.c voltage from $0 \mathrm{~V}$ to $5 \mathrm{~V}$ to a continuous power controller.

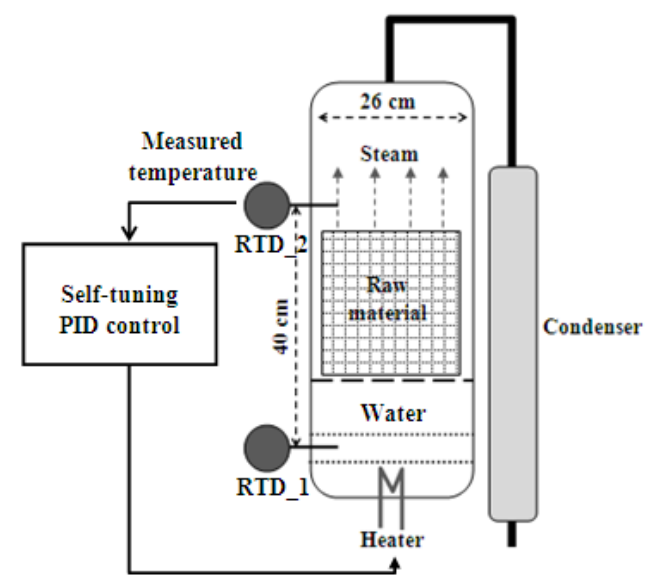

Figure 1. Steam distillation for essential oil extraction diagram

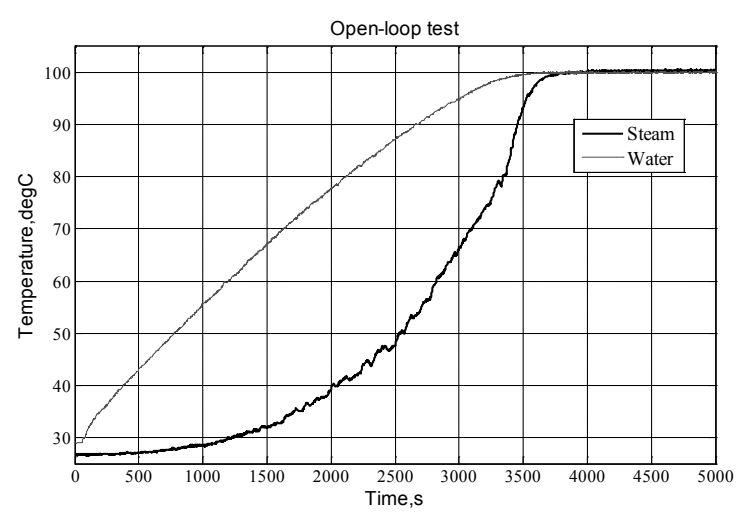

Figure 2. Open loop response of water and steam temperature

From the open-loop response, the model was identified within its linear operating temperature of $80^{\circ} \mathrm{C}$ to $100^{\circ} \mathrm{C}$. The process was fitted to a second-order system using 
System Identification Toolbox and fine-tuned to minimize the residual from experimental data. The best fit model was given by equation (3).

$$
G(s)=\frac{0.000366}{(s+0.011)(s+0.0074)}
$$

The process gain for the specified range is $4.5^{\circ} \mathrm{C} / \mathrm{V}$. Comparison between experimental data and the predicted model output gives RMSE of $0.042^{\circ} \mathrm{C}$.

\section{Self-tuning Pole Placement}

Self-tuning control (STC) contains two algorithms; one for the online parameter estimation and the other is for control law implementation. This method uses the information from model parameters that must be updated recursively in order to synthesize a new controller parameters based on specified design requirements. In some self-tuning controller, the recursive process estimation was not necessary. This type of controller is referred to as implicit self-tuning controller.

Most of the explicit STCs apply certainty equivalence principle where model uncertainties during parameter estimation were not considered. It is assumed that these values correspond to their actual values. Theoretical details of the principal can be found in prominent textbooks of adaptive control[16][17]. Figure 3 shows a block diagram of an explicit self-tuning control structure.

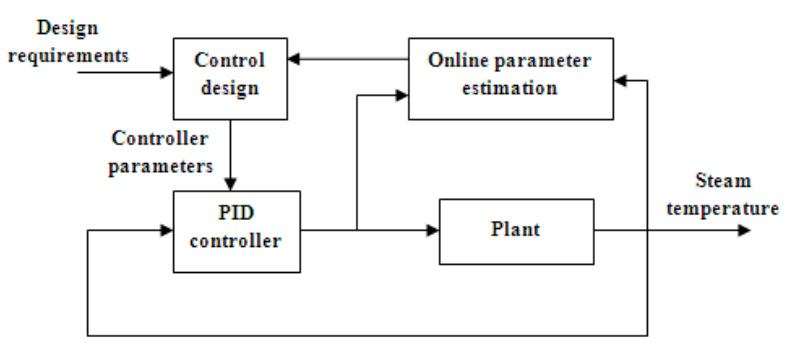

Figure 3. Explicit self-tuning control structure

The control structure based on pole-as signment method is shown in Figure 4.

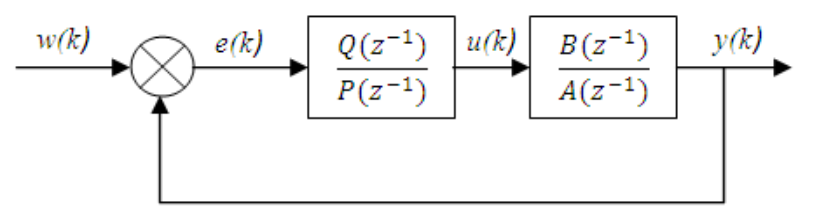

Figure 4. Self-tuning PID pole-placements

For explicit self-tuning control, a parametric model is more appropriate because the plant parameters need to be updated at each sampling interval. For this study, second-order ARX structure had been identified as the most suitable model structure. The process transfer function is given by

$$
G_{p}(z)=\frac{Y(z)}{U(z)}=\frac{B\left(z^{-1}\right)}{A\left(z^{-1}\right)}
$$

where $\mathrm{A}\left(\mathrm{z}^{-1}\right)$ and $\mathrm{B}\left(\mathrm{z}^{-1}\right)$ are polynomials in the form

$$
A\left(z^{-1}\right)=1+a_{1} z^{-1}+a_{2} z^{-2}
$$

$$
B\left(z^{-1}\right)=b_{1} z^{-1}+b_{2} z^{-2}
$$

The transfer function of a controller is

$$
G_{R}(z)=\frac{U(z)}{E(z)}=\frac{Q\left(z^{-1}\right)}{P\left(z^{-1}\right)}
$$

Where $\mathrm{E}(\mathrm{z})=\mathrm{W}(\mathrm{z})-\mathrm{Y}(\mathrm{z})$ or the closed-loop system error and

$$
\begin{gathered}
P\left(z^{-1}\right)=\left(1-z^{-1}\right)\left(1+\Upsilon_{z^{-1}}\right) \\
Q\left(z^{-1}\right)=q_{0}+q_{1} z^{-1}+q_{2} z^{-2}
\end{gathered}
$$

By substituting $\mathrm{P}\left(\mathrm{z}^{-1}\right)$ and $\mathrm{Q}\left(\mathrm{z}^{-1}\right)$ into equation (5), the controller output becomes

$$
\begin{gathered}
u(k)=q_{0} e(k)+q_{1} e(k-1)+q_{2} e(k-2)+ \\
(1-\Upsilon) u(k-1)+\Upsilon u(k-2)
\end{gathered}
$$

$\mathrm{q}_{0}, \mathrm{q}_{1}, \mathrm{q}_{2}$, and $\Upsilon$ will be determined according to design specifications. The closed-loop transfer function is then becomes

$$
G(z)=\frac{Y(z)}{W(z)}=\frac{B\left(z^{-1}\right) Q\left(z^{-1}\right)}{A\left(z^{-1}\right) P\left(z^{-1}\right)+B\left(z^{-1}\right) Q\left(z^{-1}\right)}
$$

with characteristics polynomial of

$$
A\left(z^{-1}\right) P\left(z^{-1}\right)+B\left(z^{-1}\right) Q\left(z^{-1}\right)=D\left(z^{-1}\right)
$$

where $\mathrm{D}\left(\mathrm{z}^{-1}\right)$ is the desired characteristics polynomial in the form

$$
D\left(z^{-1}\right)=1+d_{1} z^{-1}+d_{2} z^{-2}+d_{3} z^{-3}+d_{4} z^{-4}
$$

For easier determination of system overshoot and response speed, the following characteristics polynomial is preferable[19].

$$
D\left(z^{-1}\right)=(z-\alpha)^{2}[z-(\alpha+j \omega)][z-(\alpha-j \omega)]
$$

The characteristics polynomial in equation (10) has double real poles given by $\alpha$ and a pair of complex conjugate poles where $\alpha^{2}+\omega^{2}<1$. Parameter $\alpha$ influenced the speed of the closed-loop system while $\omega$ determined the desired overshoot. Equation (8) and (10) give a set of four linear algebraic equations as follows:

$$
\begin{gathered}
q_{0} b_{1}+\gamma=c+1-a_{1} \\
q_{0} b_{2}+q_{1} b_{1}+\gamma\left(a_{1}-1\right)=d+a_{1}-a_{2} \\
q_{1} b_{2}+q_{2} b_{1}+\gamma\left(a_{2}-a_{1}\right)=f+a_{2} \\
q_{2} b_{2}-\gamma a_{2}=g
\end{gathered}
$$

where

$$
\begin{gathered}
c=-4 \alpha ; d=6 \alpha^{2}+\omega^{2} \\
f=-2 \alpha\left(2 \alpha^{2}+\omega^{2}\right) ; g=\alpha^{2}\left(\alpha^{2}+\omega^{2}\right)
\end{gathered}
$$

Solving equation (11) will determine the controller parameters.

The ARX regression model in recursive form can be written as

where

$$
y(k)=\theta^{T}(k) \varphi(k-1)+e(k)
$$

is the parameter vector and

$$
\begin{gathered}
\varphi^{T}(k-1)=[-y(k-1),-y(k-2), \ldots,-y(k-n a), \\
u(k-1), u(k-2), \ldots, u(k-n b)]
\end{gathered}
$$

is the regression vector. The non-measurable random component $\mathrm{e}(\mathrm{k})$ is assumed to be zero for simplicity. The quality of the regression model is evaluated by the prediction error given by

$$
\hat{e}(k)=y(k)-\hat{y}(k)
$$

where $\hat{y}(k)$ is the predicted output.

Parameter vector is therefore can be determined by minimizing the loss function given in equation (15) using the 
recursive least square (RLS) algorithm that is widely used and can be referred in[20]and[21] for mo re detail.

$$
J_{k}(\theta)=\sum_{i=0}^{k} e^{2}(i)
$$

The algorithm had been verified with known parameters ARX model in equation 16.

$$
\begin{aligned}
& A(q)=1-1.988 q^{-1}+0.988 q^{-2} \\
& B(q)=0.006521 q^{-1}-0.006378 q^{-2}
\end{aligned}
$$

Online estimation using the RLS algorithm produced the estimated values given in Table 1 . All the estimated values are within acceptable range of deviation.

Table 1. True and estimated values of arx model using RLS

\begin{tabular}{|c|c|c|c|c|}
\hline & $\mathrm{a} 1$ & $\mathrm{a} 2$ & $\mathrm{~b} 1$ & $\mathrm{~b} 2$ \\
\hline True value & -1.988 & 0.988 & 0.006521 & -0.006378 \\
\hline $\begin{array}{c}\text { Estimated } \\
\text { value }\end{array}$ & -1.982 & 0.981 & 0.006521 & -0.006334 \\
\hline Deviation & $\begin{array}{c}0.006 \\
(0.3 \%)\end{array}$ & $\begin{array}{c}0.007 \\
(0.7 \%)\end{array}$ & $0(0 \%)$ & $\begin{array}{c}0.000044 \\
(0.69 \%)\end{array}$ \\
\hline
\end{tabular}

\section{Simulation Results}

Before the controller was implemented on the real process, some simulation analysis was done to evaluate the effect of poles location and to discuss on the effect of actuator constraint towards control performance. As had been explained in Section 2, the actuator which is the power controller has limited output between 0 to $5 \mathrm{~V}$. This constraint will limit the effect of poles location on the controlled output. From simulation study, the most optimal poles setting will be evaluated based on the output response.

\subsection{Effect of Poles Location}

When the control signal was suppressed as in experimental setup, the effect of poles location towards the output became less evident. To investigate the effect of actuator constraint, 16 controller settings was simulated. The simulation was run by varying three controller variables; sampling time, alpha, and omega. The sampling time determined a period where control signal will be updated. Sampling times were changed between 10 s and 20 s while alpha and omega were changed from 0.1 to 0.9 and evaluated consecutively. The results were compared in terms of the settling time, \% overshoot and the error in steady-state. Significant results from the simulation were summarized in Table 2.

Theoretically, smaller value of $\alpha$ will produce faster response while s maller $\omega$ will produce less overshoot. There was not much different was observed in $\%$ overshoot when $\omega$ was changed from 0.0 to 0.1 . The result can be seen from case A1 and A2. The unsaturated cases show $100 \%$ overshoot compared to $0.67 \%$ when the controller output was saturated.

Adversely, the overshoot may be caused by a fast settling time when $\alpha$ was set to 0.1 and 0.5 . This observation was obtained by comparing the results between $\mathrm{A} 2$ and $\mathrm{A} 3$. The overshoot was reduced to $8 \%$ but settling time was increased to $144 \mathrm{~s}$. The largest overshoot was expected when we set small $\alpha$ and large $\omega$ as in case A8. This case gave overshoot of $160 \%$ but the slowest to achieve steady-state because of high oscillation. Figure 5 shows the plots of A1, A2, A3 and A8.

Table 2. Output Analysis W ith and W ithout ThePresence Of Control Signal Constraint

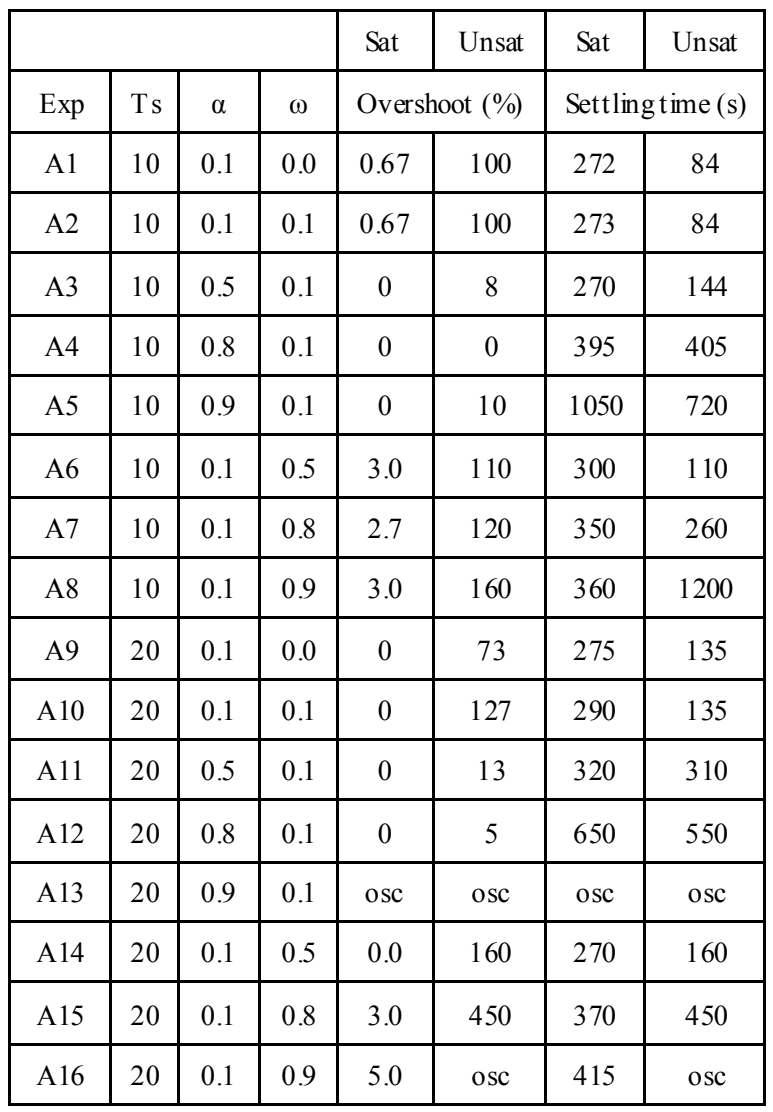

*Sat : saturated control output, Unsat: unsaturated control output, Osc: oscillatory response

From this study, it can be seen that there were mutual effect between $\alpha$ and $\omega$. So, the step response cannot be evaluated from the value of $\alpha$ or $\omega$ a lone. The best response was observed from A3 where this setting gave no overshoot, fastest settling time and no steady-state error under both conditions. The effect of actuator constraint towards controlled output can be observed for cases A2, A3, A7, A10, and A15. Figure 6 to 10 show the output response during unconstrained and constrained controller output for the respective cases.

The output responses show almost similar results when the controller output was saturated. This is shown in Figure 11. Therefore, optimal setting of poles location was made from the unconstrained condition where A3 satisfy the control requirements for this process. 


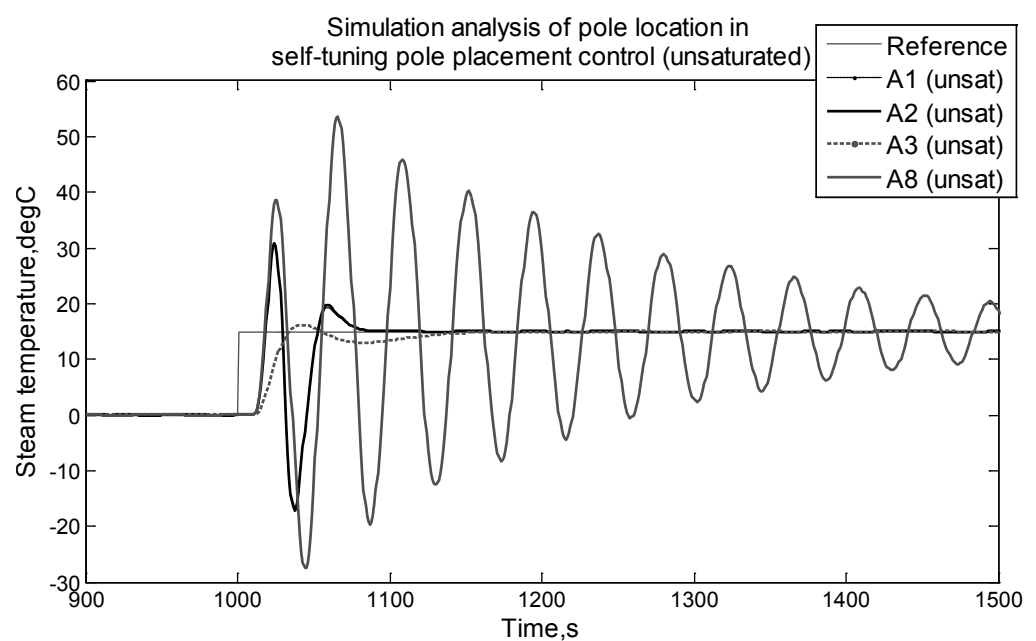

Figure 5. Effect of poles location on the closed-loop response for cases A1, A2, A3, and A8

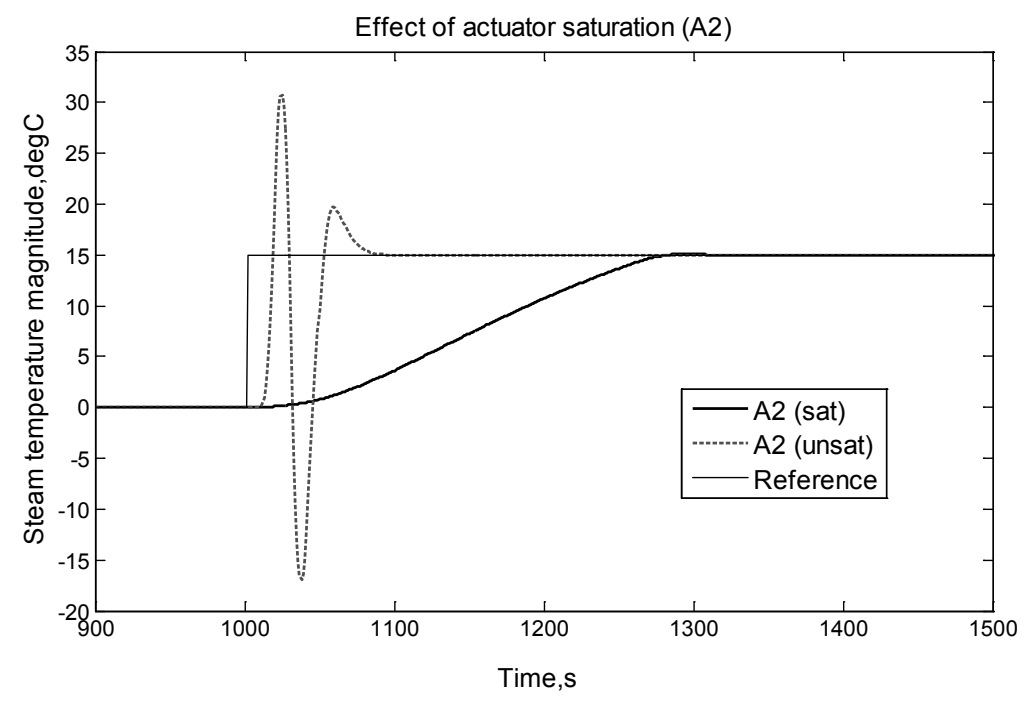

Figure 6. Case A2 for saturated and unsaturated control output

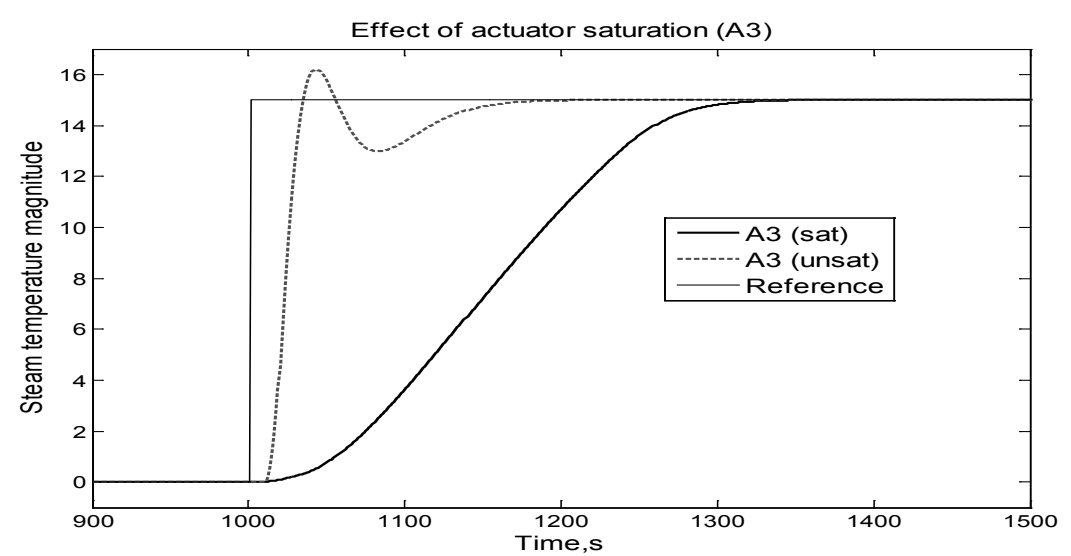

Figure 7. Case $\mathrm{A} 3$ for saturated and unsat urated control output 


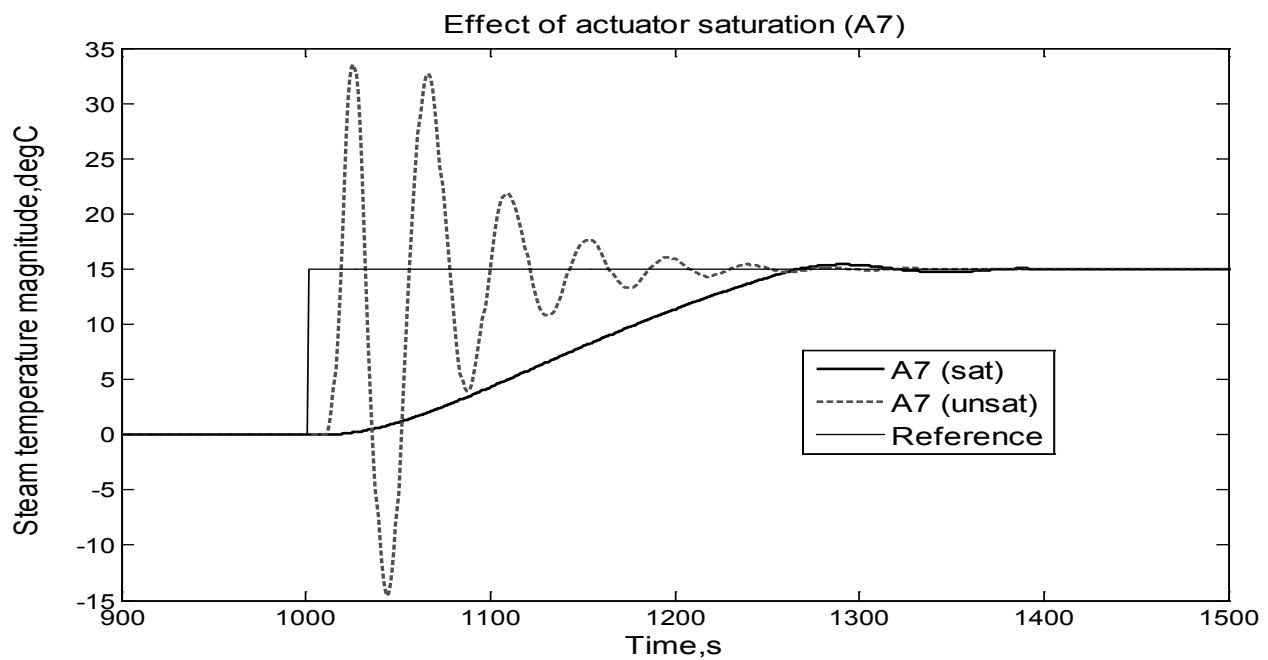

Figure 8. Case A7 for saturated and unsaturated control output

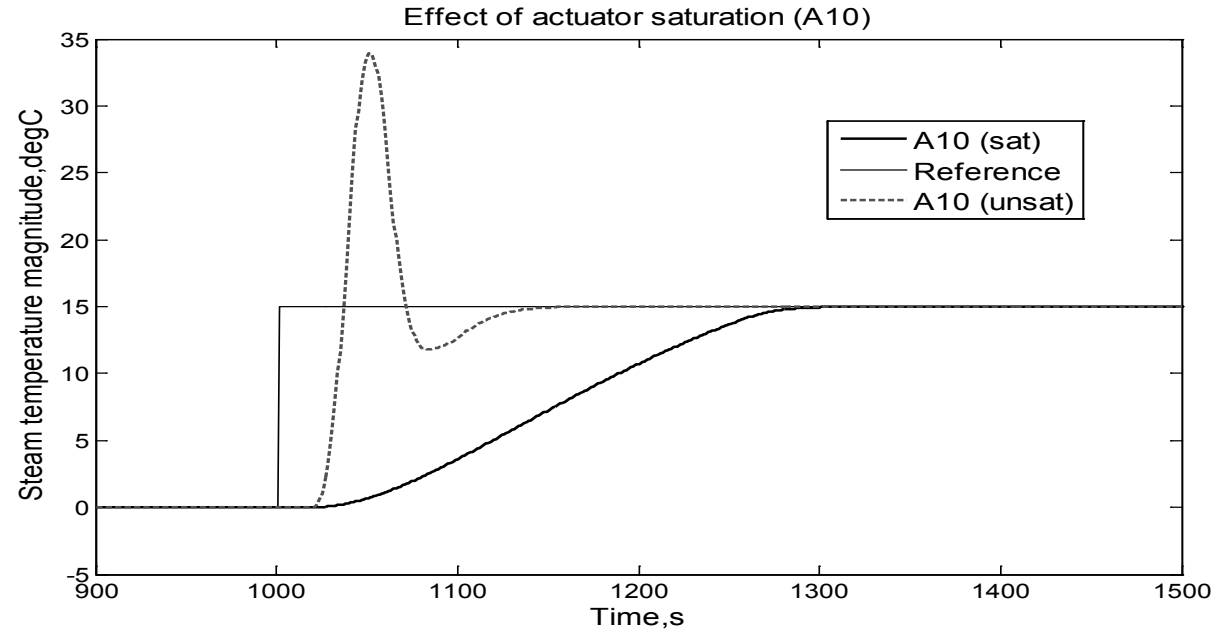

Figure 9. Case A10 for saturated and unsaturated control output

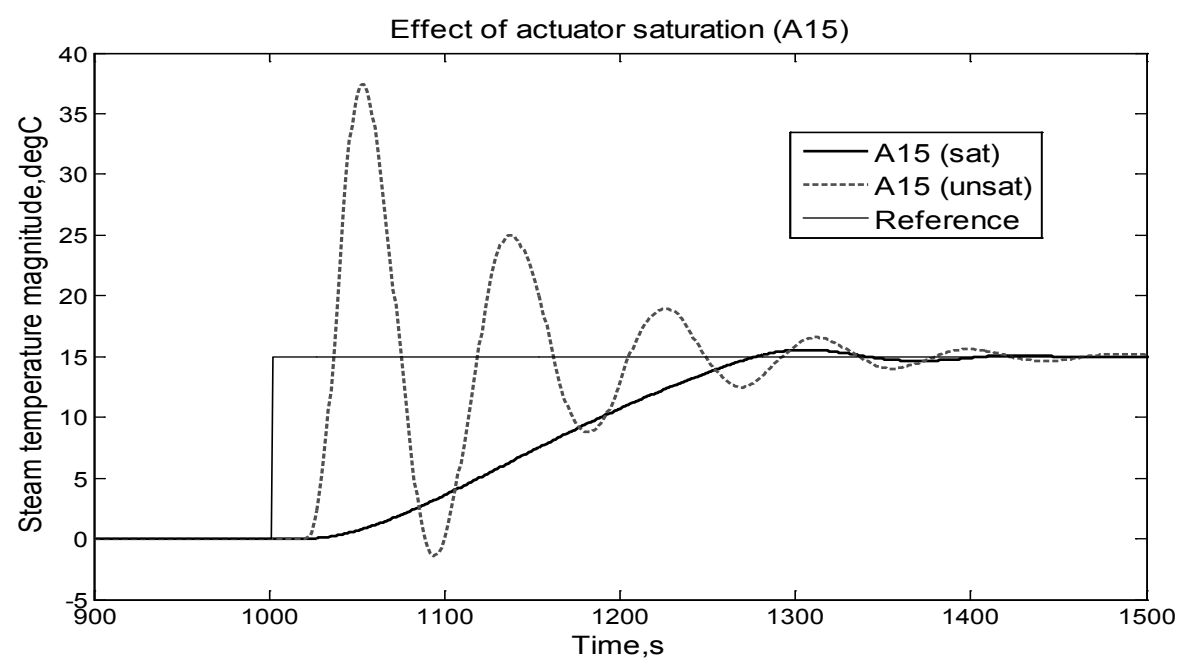

Figure 10. Case A15 for sat urated and unsat urated control output 


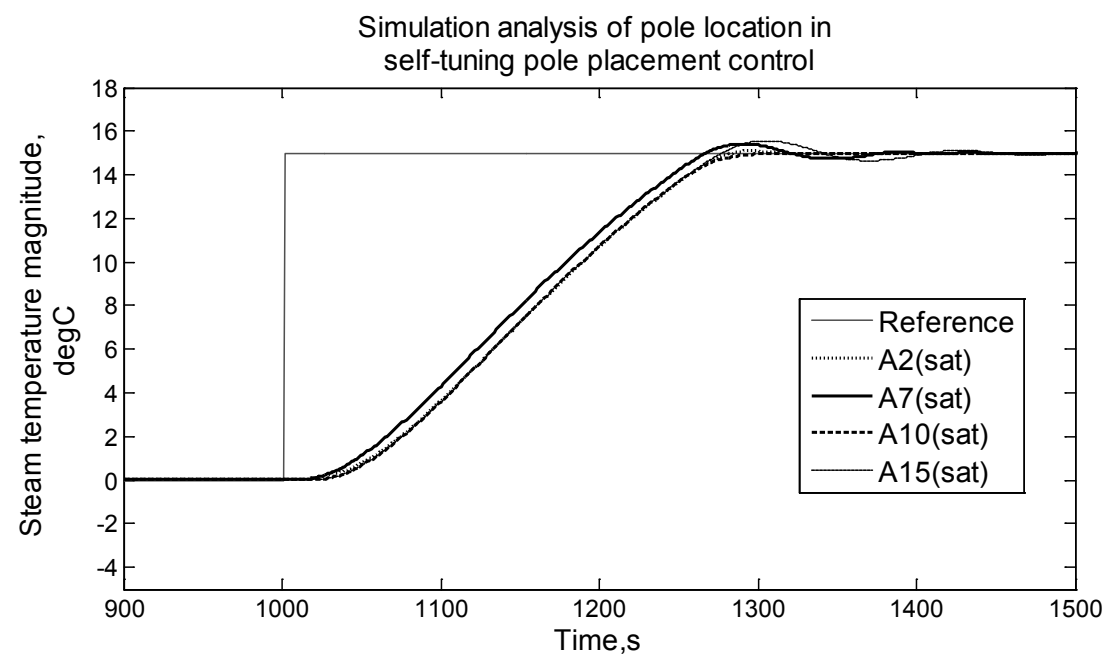

Figure 11. Closed-loop response with different pole locations under sat urated control output

\subsection{Effect of Sampling Time}

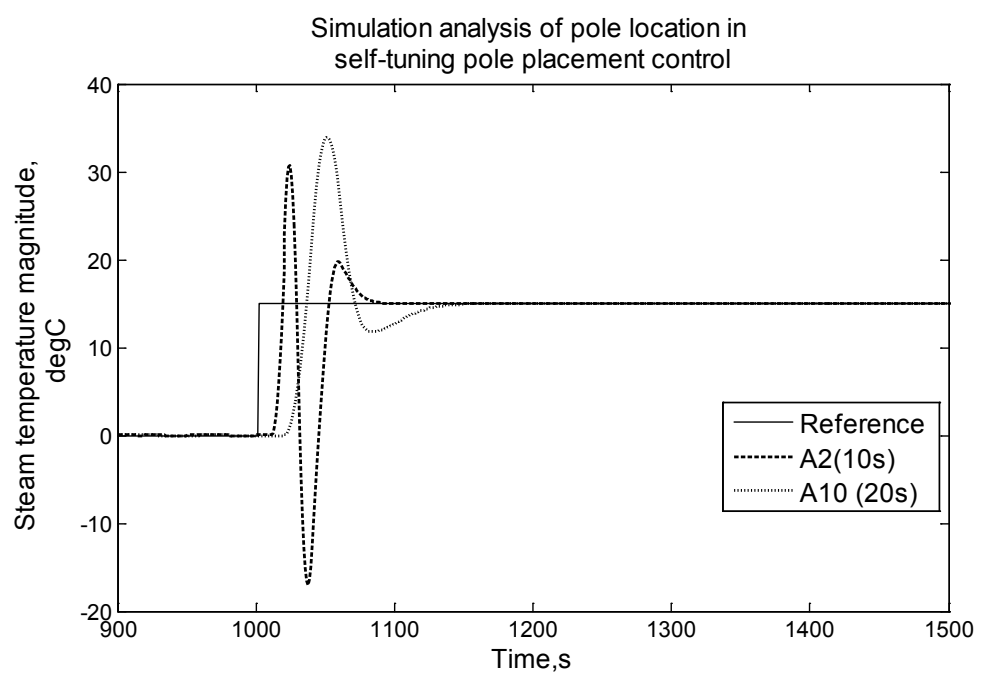

Figure 12. Effect of sampling time for cases A2 and A10

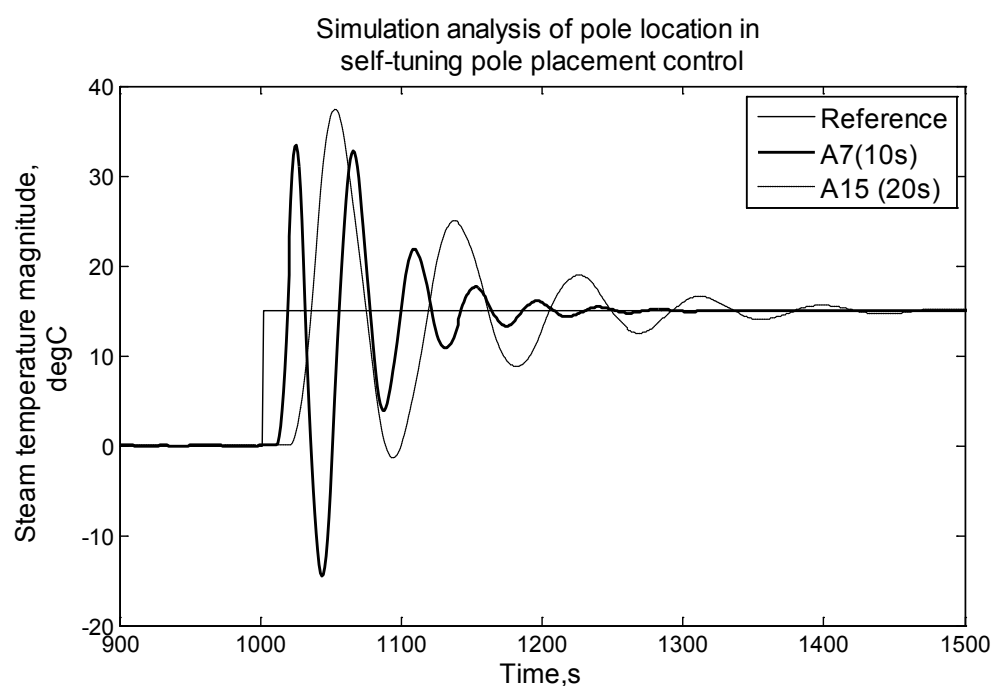

Figure 13. Effect of sampling time for cases A7 and A 15

The effect of sampling time selection for controller update was evaluated between 10 seconds and 20 seconds. Steam temperature possessed a slow varying dynamics caused by the transport delay and large time constant. It took few seconds for the process to react upon the control signal. From figure 2 , it is obvious that the time constant of the process is 
in the order of tenth of seconds. Based on researcher experimental experiences, sampling time of 10 seconds would be adequate to capture the changes in process dynamics. Sampling time faster than this will only caused chattering in control signal and jeopardized the system performance.

Figure 12 shows comparis on between two sampling times; 10 seconds and 20 seconds. A2 and A 10 have common poles setting but A2's sampling time was 10 seconds while A10's was 20 seconds. From the figure, A2 was updated more frequent compared to A10 and consequently had smaller settling time. The same condition was observed from A7 and A 15 as shown in figure 13. Based on these observations, the sampling time for the self-tuning controller was set to 10 seconds.

\section{Experimental Results}

From simulation results, the optimal setting for self-tuning controller was finalized. The sampling time was set to 10 seconds, $\alpha=0.5$ and $\omega=0.1$. The computer-based control was implemented using MATLAB Simu link R2009a. Initial condition for the parameter estimation was set to $\{0.01 ; 0.02$; $0.03 ; 0.04\}$ respectively. The controller was set to regulate the steam temperature at $85^{\circ} \mathrm{C}$. Figure 14 shows the experimental steam temperature output that was regulated fro $m$ room temperature. It took about 3000 s for the steam to reach $50^{\circ} \mathrm{C}$ and gain its energy. The steam temperature respond as expected where there was no overshoot and the steam temperature was maintained at $85^{\circ} \mathrm{C}$ for the whole duration.

It is considered as normal in the real process to have some fluctuations in the output caused by external disturbances and uncertainties. The rule of thumb in process regulation is to maintain the controlled variable within $\pm 2 \%$ boundary. This gave tolerance of $\pm 2^{\circ} \mathrm{C}$ from the set point temperature. Figure 15 shows a closed-up view during the steady-state. Steam temperature fluctuates between $84^{\circ} \mathrm{C}$ to $86^{\circ} \mathrm{C}$ from the final temperature and within acceptable boundaries.

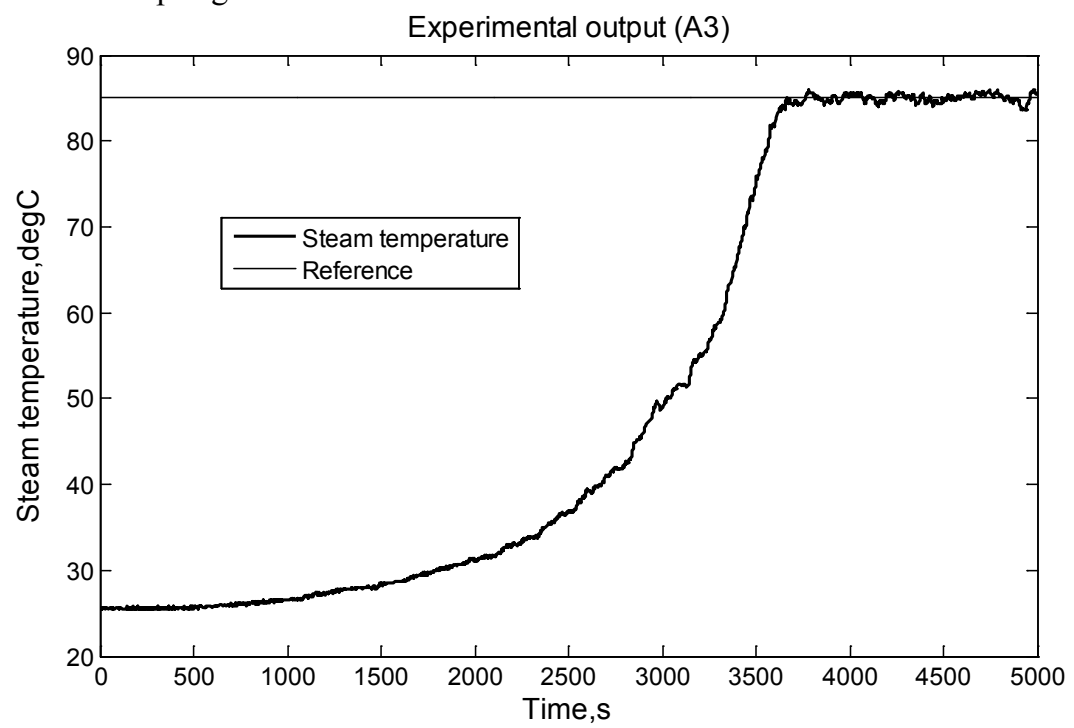

Figure 14. Experimental output when set to $\mathrm{A} 3$ and steam temperat ure regulated at $85^{\circ} \mathrm{C}$

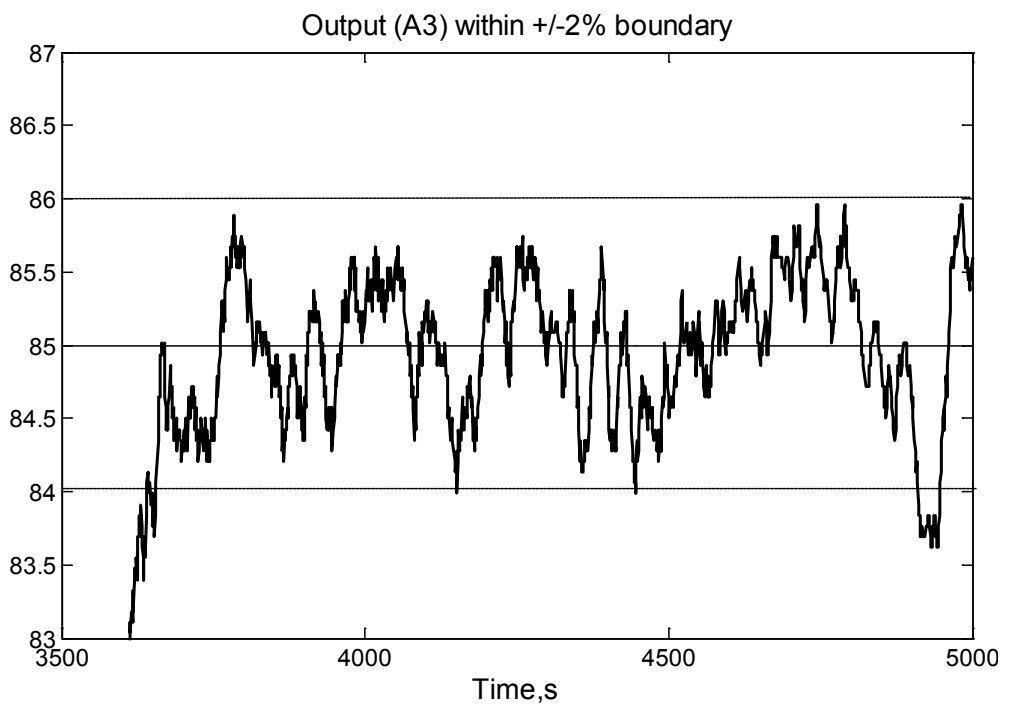

Figure 15. Steady-state response lies within $\pm 2 \%$ output boundary 


\section{Conclusions}

The self-tuning PID based on pole-placement method was adopted to regulate the steam temperature of a steam distillation essential oil extraction process. The controller cascaded four additional poles to the process plant to influence the closed-loop response. These poles tailored to the percentage overshoot and response speed requirements which is of utmost important in process control. Simulation study helped to determine the optimal setting of the poles. Experimental implementation on a real process proved that the self-tuning controller can regulate the steam temperature at a desired set point without temperature overshoot when the poles were set to 0.5 and 0.1 with $10 \mathrm{sec}$. sampling time.

\section{ACKNOWLEDGEMENTS}

This research is supported by UiTM Excellence Fund 600-RMI-ST-DANA-5/3/DST(43/2010) and Ministry of Higher Education fund (600-RMI-ST-FRGS 5/3/Fst $(85 / 2010))$. The authors would like to thank the Faculty of Electrical Eng ineering, UiTM for providing the facilities to conduct this research and for the financial supports throughout the process.

\section{REFERENCES}

[1] P. Masango, "Cleaner production of essential oils by steam distillation," Journal of Cleaner Production, vol. 13, pp. 833-839, 2005.

[2] N. A. Mohamed, "Study on Important Parameters Affecting the Hydrodistillation for Ginger Oil Production," 2005.

[3] E. Cassel, R. M. F. Vargas, N. Martinez, D. Lorenzo, and E. Dellacassa, "Steam distillation modeling for essential oil extraction process," vol. 9, pp. 171-176, 2008.

[4] M. R. Wingard and R. C. Phillips, "Solvent Extraction IV. The Effect of Temperature on Extraction Rate," Journal of American Oil Chemists Society, no. 11, pp. 149-152, 1951.

[5] N. C. Nikolic, S. M. Cakic, S. M. Novakovi, M. D. Cvetkovic, and M. Z. Stankovic, "Effect of Extraction Techniques on Yield and Composition of Soybean Oil," Macedonian Journal of Chemistry and Chemical Engineering, vol. 28, no. 2, pp. 173-179, 2009.

[6] H. Fadel, F. Marx, A. El-Sawy, and A. El-ghorab, "Effect of extraction techniques on the chemical composition and antioxidant activity of Eucalyptus camaldulensis var. brevirostris leaf oils," Z Lebensm Unters Forsch A, vol. 208, pp. 212-216, 1999.

[7] Z. Burkus and F.Temelli, "Effect of Extraction Conditions on
Yield , Composition, and Viscosity Stability of Barley ß-Glucan Gum," vol. 75, no. 6, pp. 805-809, 1998.

[8] R. N. Silva, P. O. Shirley, J. M. Lemos, and a. C. Gonçalves, "Adaptive regulation of super-heated steam temperature: a case study in an industrial boiler," Control Engineering Practice, vol. 8, no. 12, pp. 1405-1415, Dec. 2000.

[9] H. Liu, L. Nie, and H. Huang, "Superheated Steam Temperature Control Based on Active Disturbance Rejection Control \& Neural Network," in Asia Pasific Power and Energy Engineering Conference, 2010, pp. 25-28.

[10] D. Zhao and P. Liang, "Support Vector Machine Predictive Control for Superheated Steam Temperature Based on Particle Swarm Optimization," in Asia Pacific Power and Energy Engineering Conference (APPEEC), 2010, no. 05006518, pp. 1-4.

[11] G. L. Hou, J. H. Zhang, J. Wang, and Q. H. Wu, “ADAPTIVE SLIDING MODE AND FUZZY GAIN SCHEDULING CONTROL FOR STEAM TEMPERATURE IN POWER PLANTS," in UK International Conference on Control, 2003.

[12] K. Astrom and T. Hagglund, "Revisiting the Ziegler-Nichols step response method for PID control," Journal of Process Control, vol. 14, no. 6, pp. 635-650, Sep. 2004.

[13] D. P. Atherton and S. Majhi, "Limitations of PID Controllers," in Proceedings of the American Control Conference, 1999, pp. 3843-3847.

[14] A. O Dwyer, "A summary of PI and PID controller tuning rules for processes with time delay. Part 1 : PI controller tuning rules," in IF AC Workshop on Digital Control, 2000, pp. 175-180.

[15] A. O Dwyer, "PI and PID controller tuning rules for time delay processes : a summary . Part 2: PID controller tuning rules," in Proceedings of the Irish Signals and Systems Conference, pp. 339-346.

[16] K. J. Burnham, K. J. Disdell, D. J. G. James, and C. A. Smith, "DEVELOPMENTS IN INDUSTRIAL APPLICATIONS OF SELF-TUNING CONTROL," ControlEng. Practice, vol. 3, no. 9, pp. 1265-1276, 1995.

[17] K. J. Astrom and B. Wittenmark, Adaptive Control. Addison-Wesley, 1995, p. 24.

[18] V. Bobal, J. Bohm, J. Fessl, and J. Machacek, Digital Self-tuning Controllers: Algorithms, Implementation and Applications. Springer, 2005, p. 317.

[19] V. Bobal and M. Kubalcik, "Self-tuning controller for temperature control of a thermo-analyzer," 1994, pp. 2-3.

[20] K. J. Astrom and B. Wittenmark, "Self-tuning controllers based on pole-zero placement," in IEEE Proceedings, 1980, vol. 127 , no. 3 .

[21] Y. Zhao, E. G. Collins, and D. A. Cartes, "Self-tuning adaptive control for an industrial weigh belt feeder," ISA Transactions, pp. 437-450, 2003. 